\title{
The effects and problems of the supply side reform of cotton
}

\author{
production in Xinjiang \\ Yawen $Y u$, Guoxin $Y u^{*}$ \\ Xinjiang Agricultural University, Urumqi \\ *Corresponding author: Guoxin Yu, professor, e-mail address: ygxwxxj@126.com
}

\begin{abstract}
Document No. 1 of the Central Committee of the Communist Party of China in 2016 propose that, increase the innovation drive in agricultural modernization, change the mode of agricultural development, push the reform of the agricultural supply side, maintain farmers' income and develop agriculture steadily ${ }^{1}$. Because of the special differences between the Xinjiang state farms Construction Corps and the local system: the local farmer's land area is small, and the production is more dispersed; while Xinjiang state farms Construction Corps area is large, and the cotton production has unified management from planting to harvesting, basically realized large-scale, precision and mechanization. Therefore, in the process of supply side reform in Xinjiang, the overall performance is that the gap between the Xinjiang state farms Construction Corps and the local is huge, the overall effect of the reform in the supply side of the Corps is better. Our findings revealed, if local farmers want to deep reforms in the supply side, they need to move from decentralization to unity, and set up professional cooperatives. Thus the scattered land of farmers could be unified managed by the cooperatives, which will reduce production costs and improves efficiency, and at the same time, the income of farmers is guaranteed, and rural labor force is liberated.
\end{abstract}

Key words: Xinjiang; cotton; production; supply side reform; effect; problem

\section{Introduction}

Promoting the structural reform of agricultural supply side, improving the comprehensive efficiency and competitiveness of agriculture is the main direction of the reform of the agricultural policies in China at present and in the future ${ }^{2-3}$. Promoting structural reforms in the supply side of agriculture is also the subject of central document No.1 in 2017. This paper pointed out that optimizing the industrial structure, vigorously promoting the quality and 
efficiency of agriculture, economic crops should optimize varieties, quality and regional distribution, consolidating cotton production in major producing areas.

Xinjiang is the main cotton producing area, cotton output accounts for about half of Xinjiang's total agricultural output value. According to 2015 statistical yearbook data show that Xinjiang cotton planting area accounts for $40.4 \%$ of the total planting area of Xinjiang crops, accounting for $50.1 \%$ of the total cotton planting area in China, cotton production accounts for $62.5 \%$ of the total cotton output. Cotton industry occupies a pivotal position in the economic and social development of Xinjiang.

\section{The actual effect in supply side reform: the gap between the Xinjiang state farms}

\section{Construction Corps and the local cotton area is large}

\subsection{The technical service system of the Xinjiang state farms Construction Corps is perfect, and the efficiency of cotton production is high}

Because of Xinjiang state farms Construction Corps' strict institutions, a company needs to guarantee three people to manage the production, including a technician, a plant protector, and a company commander. Every day, the commander of the company and other officials will inspect the field to see if there are any problems. Every year in winter, the association of science and technology will concentrate on training all the farmers in the corps, and invite all kinds of agricultural experts or university scholars from inside and outside the city to conduct lectures and training on new cotton production technologies, such as the use of pesticides and fertilizers, answer questions in the process of cotton production. The pesticide and fertilizer application have a designated person for measurement, through the use of drip irrigation belt, how much water, how much fertilizer and what fertilizer should be placed at each stage of cotton growth, there is a corresponding data collection.

Comparatively, the local farmers is very lack of corresponding technical guidance, because the local government lacks fixed technical staff , what kind of cotton varieties, playing what medicine and fertilizer, the farmers is very blind. People tend to see what pesticides and how much are being played by the farmers around them, after consulting with each other, they make their own decision of how to use. Because there is no accurate measurement and guidance, the results are very random after planting, if the heat weather lasts too long, local red spider and other harmful cotton production insects appear frequently, they need to spray agricultural chemicals 7-8 times.Some insects produce resistance, and the result is not satisfactory. 


\subsection{The mechanization of Xinjiang state farms construction corps is high.}

The Corps collectively use large machinery, which can greatly reduce the amount of labor used, save the cost of purchasing materials, and reduce the cost of planting. In the whole production(from sowing to harvest), Xinjiang state farms Construction Corps using machinery including ploughing, sowing, mulching, watering, fertilizing, spraying, picking and packing. They grow thousands of acres of land, usually requiring little labor and the cost is very low.

However, because most of the local farmers grow cotton, the plots are scattered and the area is small, and the cultivated varieties are different, the large machinery of the Corps cannot be used locally. At the same time, the area is too small and the output is insufficient, some of the large private machines are also reluctant to harvest, because of their low benefits. Therefore, a lot of farm work, such as seeding, plastic film mulching, pesticide spraying, harvesting and so on, are still need people to do. The production efficiency is not high, and the cost is very expensive. Some farmers reflected that seeds and large planter machines which the local farmers used now were eliminated by the corps long time ago. From the side, it can also reflect the huge gap between the corps and the local areas in scale and mechanization.

\subsection{Compared with local farmers, it is easier for the state farms Construction corps to} obtain loans.

As a result of the system, the Corps made loans as a whole, in accordance with the requirements of 500 loan 1000 collective loans. To the Corps seventh division, for example, last year they made loans from the rural credit cooperatives, and this year is in the national villages and towns bank lending. Because collective lending is more secure, farmer loans are easier and interest rates are lower. Therefore, the state farms Construction corps has obvious advantages. Local farmers, however, are less likely to obtain bank loans due to their small size, and the loan amount is lower, interest rates are higher, it is not conducive to expanding agricultural investment.

\subsection{In the process of cotton trade, the differences between the state farms Construction corps and the local farmers are also obvious.}

Corps farmers unified the cotton to the Corps, and then contact the local cotton enterprises by the corps, because of the large size, the cotton sale price is much more stable than local small farmers. However, it is also prone to corruption in the process. The market price and the purchase price are not unified, as for farmers farming, sales revenue control is weak .Local 
farmers, though, have the freedom to choose whom to sell, but because they don't have longdistance transportation capacity, and the scale is too small to decide the purchase price. Farmers can only passively accept the price of cotton ginning factory, facing greater risk of market price fluctuations.

\section{Problems existing in the reform of cotton supply side}

\subsection{Cotton target price subsidies issued existing problems}

The state farms Construction corps issued cotton subsidies mainly rely on sell kilograms to calculate, although last year the country decided the target price of cotton 19100 yuan per ton, after conversion, cotton purchase price is 8 yuan per kilogram. But the actual price paid to farmers in the Corps is only about 6.8-7.2 yuan per kilogram.

Local farmers argue that subsidies delivery is too slow, subsidies for the previous year were not available until the 8-9 month of the following year. This is because the subsidy data needs to be reported to the county development and Reform Commission and the county government from the production team step by step, and the basic level of data is large, and the number of government personnel is limited.

\subsection{Cotton prices fluctuate frequently,cotton processing enterprises depress the purchase price phenomenon is serious.}

For local farmers, cotton prices given by cotton processing plants are determined by the number of farmers who were selling cotton, if fewer cotton farmers are sold, the purchase price is high, and if the number of people is large, the purchase price is low. Most cotton processing plants in order to collect more cotton, reduce costs, and a large number of artificially depress the purchase price, especially in late October, which is the most serious. It was also known as "after the frost flowers". This is mainly because that the ginning factory in order to save costs and reduce loan interest, reluctant to bank multiple loans. And for farmers,cotton will be yellow after placed a year, which will affecting quality, so they have to sell to the cotton ginning factory at low prices.

\subsection{The overall quality of personnel engaged in agricultural science and technology popularization is not high.}

Due to the prevalence of population aging in recent years, The state farms Construction corps is also facing this problem, a large number of old technical backbone retired,while young people are mostly willing to work in big cities outside, do not want to do farm work ${ }^{4}$, do 
technicians and so on. It is also very difficult to attract talent from other place. So there are the lack of technical personnel and new staff.

Local farmers need scientific and technical personnel to guide at the grassroots level for a long time, because the local farmers' cultural level is limited, when the local farmers go to the corps to study, the farmers cannot fully understand their technical content, the training effect is limited, and most farmers still belong to blindly follow the trend of planting. As a result, crop prices tend to fluctuate over the years. Many farmers reflect the need for high-level personnel to guide the selection of breeding or crop types.

\subsection{The difficult of residual film cleaning}

Because of the large amount of thin mulch used for a long time, the remaining fragments of plastic film in the land have reached the level of $30 \mathrm{~kg}$ of residual film per 0.066 hectares. The residual plastic film resulted in sequelae, such as soil compaction, cotton seed germination difficulties, and no germination, or cotton cannot be rooted down at the long seedling stage. This problem seriously affects the yield of cotton and the production of subsequent cotton.

Large amount of mulch film cannot be degraded by the soil, and it is likely to be mixed with cotton during the harvesting period. Traceable standard requirements which are carried out at present for each bale of cotton is that a ton of cotton only allowed 0.2 grams of impurities within, but because of the plastic film problem which make it very easy to exceed the standard. Although the corps are now producing biodegradable film, but the results are poor. So, since last year, the Corps seventh division began to use thickened plastic film, in 2016 they used 0.008-0.01mm mulch, while in 2017 0.012mm mulch was used. However, since the cost of per kilogram of plastic film has risen from 2 yuan to 6.18 yuan, not many farmers are willing to adopt it.

\section{Conclusions}

Under the policy of cotton target price subsidy, cotton production in Xinjiang is stable. Although farmers in different areas have also grown tomatoes, beets, corn and wheat at the same time, because cotton is easier to store than tomatoes and grapes, and the price is subsidized by the subsidy policy, the risk of planting cotton is small, and the production cost is greatly reduced after the mechanization of cotton became popular. Thus, most farmers prefer to grow cotton. 
Cooperatives can provide more scientific management methods and technical support, and develop large-scale production ${ }^{5}$. Participating in cooperatives can collectively purchase large machinery, unify cotton varieties, carry out unified planting, unified management, unified harvesting and unified sale of cotton. In the acquisition of cotton, the processing plant is also more inclined to buy cooperatives cotton. This is because cotton varieties are more unified, quality is more secure. Therefore, joining cooperatives can greatly reduce cotton production costs and operational risks, and stabilize the purchase price and production quality of cotton. The government should strengthen the construction of agricultural technology popularization team, improve the responsibility system of agricultural extension, increase investment in farmers' scientific and technological training, promote rational flow of agricultural scientific and technological personnel, speed up the research and development of plastic film recycling machinery, replace the extremely high cost of manual pickup, accelerate the development and popularization of degradable plastic film technology.

\section{Acknowledgements}

This work was supported by research project of key disciplines of agriculture, forestry and economy management in Xinjiang Province ; the National Natural Science Foundation of China, Project label: 71463058.

\section{References}

1. Wang Ping, Wang Qinmei, Regional capability difference and its improvement of agricultural supply side structural reform ,J. economist, 04 (2017) 89-96.

2. Chen Chen, Research on modern agricultural industrialization consortium from the perspective of supply side reform. Generation mechanism, operation mechanism and empirical analysis, J. advances in science and technology and countermeasures,33 (2016) 78-83.

3. Kong Xiangzhi, Basic connotation and policy suggestion of structural reform of agricultural supply side ,J. reform, 02 (2016) 104-115.

4. Chen Huaning, Analysis of the training of farmers' science and technology in China. ,J. agricultural economy, 01 (2007) 19-22.

5. Zheng Fengtian ,promoting the reform of the agricultural supply side and building a beautiful countryside -- the four highlights of the Central Document No. 1 this year,J. price theory and practice 01 (2016) 26-29. 